\title{
A blood pressure clinic in a developing country
}

\author{
M. E. K. AHMED \\ M.B., B.S., M.R.C.P. (U.K.) \\ Department of Medicine, Faculty of Medicine, University of Khartoum, Sudan
}

\begin{abstract}
Summary
There are few studies of hypertension in Sudan. In this report, 124 patients attending a newly established hypertension clinic are studied, most of whom were taking irregular treatment initially. Seventy-three (59\%) had a strong family history of hypertension. There was a very low incidence of cigarette smoking (13.7\%), and alcohol consumption (4.8\%).

As with blacks in the U.K. and the U.S.A., the commonest complications were cerebrovascular accidents and congestive cardiac failure. Most of the patients had moderately elevated blood pressures on the first visit, which fell significantly after 3 and 6 months of clinic attendance. Methyldopa and thiazides were the commonest drugs used, but a small pilot survey demonstrated that beta-blockers were effective. The high cost and poor availability of drugs contribute to poor compliance in these patients.
\end{abstract}

KEY WORDS: blood pressure clinic, developing country.

\section{Introduction}

Elevated blood pressure is the most potent contributor to cerebrovascular and cardiovascular mortality. The prevalence of high blood pressure in developing countries, especially in urban societies, is believed to be similar to that in western populations (Sever, 1981; Beevers and Ahmed, 1980), but few studies have been carried out. The quality of control of blood pressure in patients receiving antihypertensive treatment is a more important predictor of risk than the severity of the hypertension before therapy. This implies that long-term supervision of therapy is necessary but, in developing countries, many adverse factors render proper control of blood pressure difficult to accomplish.

This paper reviews the degree of out-patient blood pressure control in a newly established hypertension clinic in Omdurman, Sudan.

\section{Patients and methods}

One-hundred and twenty-four patients with elei vated blood pressure attending the Omdurman $\mathrm{H}_{5} \mathcal{S}_{-}$ pertension Clinic were included in this study. Soms of these patients had previously irregularly attended a general medical clinic or local health centres; otheris were either not under medical care or were new hypertensives. Patients with satisfactory blood pressure control at the initial visit were excluded from the study.

At the first attendance, a special flow she including all the relevant data concerning history, physical examination and routine investigations $9 x$ completed for each patient. Previous treatment reviewed and altered according to blood pressipe control. A group of 10 randomly selected patien were given nadolol, a non-selective beta-adrenergie blocker, $80 \mathrm{mg}$ daily, in an open study. All patienty were then followed up every 2-6 weeks and the blood pressures were taken with a mercury sphygmo manometer.

\section{Results}

There were 90 women and 34 men, aged 22-7部 years [mean age $46 \pm 13$ (s.d.) years]. Women had $\frac{3}{3}$. mean weight of $72 \pm 16 \mathrm{~kg}$, while the mean weight fow. men was $70 \pm 12 \mathrm{~kg}$. Ninety-two patients $(74 \%)$ weri known to have had hypertension for a period of 6 months-15 years, the rest $(26 \%)$ were newly diags nosed cases.

Seventy-three patients (59\%) reported a history hypertension in their blood relations. Only $17 \mathrm{pa}$ tients $(14 \%)$ smoked more than 10 cigarettes a dax and only 6 patients (5\%) admitted any alcohol intake. The commonest presenting symptoms were heaf aches, breathlessness on exertion, blurring of visiofi and leg oedema. Eight patients had a history of recurrent pyelonephritis. Fundal examination was normal in all except 7 patients, 6 of whom has narrowing of retinal arteries and $A-V$ nipping, and only one had bilateral retinal haemorrhages. Twenty 
four patients (19\%) were found to have mild hypertension (diastolic BP, 90-99 $\mathrm{mmHg}$ ), 64 patients (52\%) had moderate hypertension (diastolic BP, $100-119 \mathrm{mmHg}$ ) and 36 patients $(29 \%)$ had severe hypertension (diastolic BP, >120 mmHg).

Table 1 shows the mean systolic and diastolic blood pressures at the initial visit and 1,3 and 6 months after first attending the clinic. After 3 months follow-up, 55\% of the patients achieved a diastolic blood pressure of $90 \mathrm{mmHg}$ or less.

TABLE 1. Mean blood pressure (BP) systolic and diastolic ( \pm s.d.) in 124 patients at arrival and 1 month, 3 months and 6 months after first attending the clinic

\begin{tabular}{lcccc}
\hline & Initial & 1 month & 3 months & 6 months \\
\hline Systolic BP (mmHg) & $171 \pm 30$ & $153 \pm 23$ & $151 \pm 18$ & $143 \pm 28$ \\
\% reduction & - & $10 \cdot 5 \%$ & $11.6 \%$ & $16.3 \%$ \\
Diastolic BP (mmHg) & $113 \pm 21$ & $99 \pm 18$ & $99 \pm 18$ & $93 \pm 13$ \\
$\%$ reduction & - & $12.3 \%$ & $12.3 \%$ & $17.6 \%$ \\
\hline
\end{tabular}

The mean ( \pm s.d.) blood pressures in the group of 10 patients who received nadolol fell from $180 \pm 32$ $\mathrm{mmHg}$ to $146 \pm 16 \mathrm{mmHg}$ (systolic) and from $120 \pm 22 \mathrm{mmHg}$ to $97 \pm 9 \mathrm{mmHg}$ (diastolic). Satisfactory falls were thus seen in this group treated with beta-blockade.

In 50 patients, the mean blood urea estimated was $4 \cdot 1 \pm 3 \cdot 0$, plasma sodium $136 \cdot 8 \pm 7 \cdot 0$ and plasma potassium $3.6 \pm 0.6 \mathrm{mmol} / \mathrm{litre}$.

A wide range of antihypertensive drugs were used, but methyldopa and thiazide diuretics, alone or in combination, were most common. Others included beta-adrenergic blockers, indapamide, and several combined preparations used in the hope of improving compliance.

\section{Discussion}

There was no significant difference in weight between males and females. This differs from trends seen in black patients in the U.S.A. (Stamler et al., 1975) where women were found to be more obese than men. The strong family history of hypertension can perhaps be accounted for by the high frequency of family intermarriages in the Sudan. It has been suggested that urban black patients have higher blood pressures than whites (Sever, 1981) but the reasons for this ethnic difference are unknown. The Sudanese patients differ from blacks in Britain and the U.S.A. in that for religious reasons there is a remarkably low incidence of alcohol consumption and cigarette smoking.
In this respect, they resemble Asians in Britain who consume less alcohol than whites or blacks. In view of the association between smoking and malignant hypertension (Bloxham, Beevers and Walker, 1979), the rarity of cigarette smoking may explain why only one case had retinopathic evidence of accelerated hypertension. The one such case in this series was however a non-smoker.

Most of our patients had moderately elevated blood pressures, only $29 \%$ had diastolic blood pressures of $120 \mathrm{mmHg}$ or more. This contrasts with the higher blood pressures reported in blacks attending a hypertension clinic in Britain (Munro Faure et al., 1979).

Our patients had less cardiovascular risk from smoking or alcohol consumption. The most common complications suffered were cerebrovascular accidents and congestive cardiac failure, ischaemic heart disease being less common. This is similar to the picture seen in black patients in the U.K. and the U.S.A. (Beevers and Cruickshank, 1981). None of our patients had severe renal involvement as the highest blood urea was $10.6 \mathrm{mmol} / \mathrm{dl}$.

Compliance among our patients was poor owing to a number of factors: poor availability and the high cost of drugs, difficulty in getting to the hospital because of less efficient public transport and ignorance about the disease. However, we are hoping to improve this by regular teaching and by gaining the confidence of the patients.

This communication confirms the important role of hospital-based hypertension clinics in achieving proper blood pressure control, especially in the developing world where, because of the prevalence of other endemic diseases and economic difficulties, hypertensive patients lack proper supervision.

\section{References}

BEEVERS, D.G. \& AHMED, M.E.K. (1980) Screening for hypertension. Postgraduate Doctor, 3(10), 425.

BEEVERS, D.G. \& CRUICKSHANK, J.K. (1981) Age, sex, ethnic origin and hospital admissions for heart attacks and stroke. Postgraduate Medical Journal, 57, 763.

BloXhaM, C.A., Beevers, D.G. \& WALKER, J.M. (1979) Malignant hypertension and cigarette smoking. British Medical Journal, 1, 581.

Munro-Faure, A.D., Beilin, L.J., BulpitT, C.J., Gear, J.S.S., HARPER, Gillian \& JOHNSON, B.F. (1979) Comparison of black and white patients attending hypertension clinics in England. British Medical Journal, 1, 1044.

SEVER, P.S. (1981) Racial differences in blood pressure: genetic and environmental factors. Postgraduate Medical Journal, 57, 755.

StAmler, J., RhomberG, P., SChoenberger, J.A. \& SHEkelle, R.B. (1975) Multivariate analysis of relationship of seven variables to blood pressure. Journal of Chronic Disease, 28, 527. 